\title{
Simulation and Optimization of Ground Traffic on Airports using Cellular Automata
}

\author{
Florian Mazur · Michael Schreckenberg \\ University of Duisburg-Essen, Physics of Transport and Traffic, Duisburg, Germany, \\ E-mail: florian.mazur@uni-due.de, michael.schreckenberg@uni-due.de
}

Received: 29 September 2017 / Accepted: 21 March 2018

DOI: $10.17815 / \mathrm{CD} .2018 .14$

\begin{abstract}
Due to increasing numbers of airplane operations on international airports in Germany, the efficiency of airport-ground operations becomes more and more important. Some airports, such as the international airport of Duesseldorf, have reached their capacity limit and need major improvements in order to handle the continuously growing number of airplanes and passengers. Further expansion of the airport is impossible because of limited space. To improve airport-ground operations, simulations are useful for evaluating suggestions in advance and for avoiding poor planning. Therefore the CAMAT-Model was developed (Cellular Automaton Model for Airport Traffic), seeking to simulate the dynamics of all airplanes as realistically as possible. Improvements on the current layout as well as new taxiways and new taxiing routes can be simulated.

In this paper we present the CAMAT-Model as well as examples of possible improvements at the airport of Duesseldorf and their influence on airplanes' average taxiing times.
\end{abstract}

Keywords Cellular automata - microscopic $\cdot$ airplane traffic $\cdot$ ground traffic on airports · theory $\cdot$ applied research $\cdot$ other traffic-related systems

\section{Introduction}

The expected growth rate for airplane traffic in Germany is over $2.3 \%$ per year in contrast to $0.2 \%$ for motorized private transport, $0.3 \%$ for railway transport and $-0.1 \%$ for public road transport. This leads to the fact that airplane traffic is the most increasing mode of transport [1,2] due to the continuing trend toward long-distance travel and the increasing interdependence of international commerce. 
The increase of airplane traffic has created problems on almost all international airports in Germany, including long queues of airplanes waiting for take-off in front of the runways because of the runway's limited capacity. For improvement airport surface operations have to become more efficient in order to be able to handle the increasing number of airplanes and to reduce waiting times. Simulations are useful to evaluate suggestions in advance and to avoid poor planning. The CAMAT-Model (Cellular Automaton Model for Airplane Traffic) is designed exactly for this purpose. It simulates the airplanes in a microscopic way and gives the opportunity to track every single airplane.

The main objective of this paper is to build up a realistic microscopic simulation on the airport of Duesseldorf in cooperation with the German air-traffic-control which simulates the behavior of every single airplane and the interaction between airplanes. Their changes in behavior shall be studied while changing taxiing routes or changing the layout of the taxiways. This shall also lead to a reduction of taxiing times and thereby to a reduction of fuel consumption in order to reduce environmental pollution.

\section{Cellular automata for airplane traffic}

Cellular automata models (CA), being well known from road traffic and pedestrian traffic [3-6], are a very efficient method to simulate non-linear traffic with interactions. They can capture the main features of human driving behavior and the interaction between actors [7].

With regards to airplane traffic a few models have been developed to simulate ground operations on airports $[8,9]$. These models' significant weakness is their usage of a constant taxiing speed. Studies at the airport of Duesseldorf have shown that a constant speed does not exist: taxiing speed can differ and even speed drops can be seen. One mesoscopic model based on cell transmission [10,11] is the model of Yang et al. [12] using empirical data of Guangzhou Baiyun International Airport (China). Although this model discribes the dynamic of airplanes on a high level it is not applicable to the airport of Duesseldorf due to the need of unexceptional uni-directional taxiways and traveling direction for links between taxiways. One CA model using a number of speed for taxiing is the model of Mori et al. [13,14]. It was developed for simulating ground traffic on the international Narita airport of Tokio (Japan). This model is specially tailored to this airport (e.g. the airplane detection system at this airport) however, does not use randomization, which is a very important point at the airport of Duesseldorf (see Sec. 3.1). Therefore, a modified CA model based on the experiences of the model by Mori et al. and the CA model for road traffic [5] is developed for simulating ground traffic on airports like the international airport of Duesseldorf in Germany.

The main purpose of this model is to reduce the airplanes' taxiing times for three main reasons. First, the airport itself is interested in reducing taxiing times. Each airplane taxiing needs the attention of the tower agents. Too many airplanes taxiing at the same time will increase the probability of mutual obstruction. Especially on airports with limited space like Duesseldorf this is an important task in order to allow undisturbed taxiing. Second, airplane companies are interested in reducing taxiing times in order to reduce the 


\begin{tabular}{lc}
\hline airplane & fuel burn $[\mathrm{kg} / \mathrm{s}$ per engine $]$ \\
\hline Airbus 319 & 0.09 \\
Airbus 320 & 0.12 \\
Airbus 321 & 0.13 \\
Airbus 330-200 & 0.23 \\
Boeing 757 & 0.18 \\
\hline
\end{tabular}

Table 1 Fuel burn of engines depending on airplane type. The values are illustrated for one engine and calculated by the ICAO values [15] and the ICAO engine database [16].

total ground time of airplanes as they benefit from flying airplanes and not from airplanes on the ground. A last purpose is to reduce fuel consumption. The International Civil Aviation Organization (ICAO) assumes airplanes taxiing at $7 \%$ thrust (engine power setting) [15]. Further publications using flight data recorder archives propose different values from $4 \%$ [9] up to $9 \%$ [17]. By use of the ICAO thrust value, fuel burn for the most used airplanes in Duesseldorf can be found in Tab. 1. The values are outlined for one engine. All airplanes represented in Tab. 1 have two engines. For more information about fuel consumption and emissions see [18-20].

To reach a reduction in taxiing times, different scenarios are simulated and average taxiing times are compared. In this paper taxiing times are defined as follows: for departing airplanes the taxiing time starts immediately when starting the push-back process at the gate and ends when lifting off the runway. For arriving airplanes the taxiing time starts when touching down on the runway and ends when reaching the final parking position at the gate. All possible waiting times in between, for instance in crossing situations, are part of the taxiing time. The results are used for optimizing the procedures by the German air-traffic-control on the airport of Duesseldorf in order to increase the airlines' and the passengers' satisfaction.

\section{The CAMAT-Model for airplane ground traffic}

The CAMAT-Model is a model for simulating airplane ground traffic on major international airports. It considers arriving and departing airplanes. In the model, the main steps of the Nagel-Schreckenberg-Model for road traffic [5] (acceleration, deceleration and randomization) are adopted and new rules for airplanes are supplemented. In the following section the main rules and specifications of the model and the implementation of the model on the airport of Duesseldorf are presented.

\subsection{Specifications and rules of the CAMAT-Model}

Cell size The cell size is set to $5 \mathrm{~m}$. This is small enough to map all common types of airplanes (e.g. a Cessna 152 needs 1 cell, an Airbus 320-200 and a Boeing 737-800 8 cells, an Airbus A330-200 12 cells, a Boeing 747-400 14 cells, and an Airbus 380-800 15 cells). 
Time step The time step is $1 \mathrm{~s}$ due to the reaction time of human beings and a parallel update is used.

Acceleration, breaking and randomization The velocity of airplanes on the ground is limited to 2 cells per second $(10 \mathrm{~m} / \mathrm{s})$ which is the maximum allowed speed for taxiing. On runways the maximum speed is unlimited. This means that departing airplanes accelerate as quickly as possible to reach their take-off speed and lift off the runway. At this point, the airplane leaves the simulated network and the runway is unusable for other airplanes. Arriving airplanes use their landing speed until touch-down and decelerate until reaching their taxiing speed.

Acceleration and deceleration depend on the airplanes' weight class, which is classified based on the airplanes' maximum take-off weight (MTOW) by the ICAO [21]:

- Light (L) MTOW of 7,000 kg (15,000 lb) or less

- Medium (M) MTOW of greater than $7,000 \mathrm{~kg}$, but less than $136,000 \mathrm{~kg}(300,000$ lb)

- Heavy (H) MTOW of $136,000 \mathrm{~kg}(300,000 \mathrm{lb})$ or greater

- Super (J) refers only to Airbus A380 and Antonov An225

In the CAMAT-model an airplane can accelerate one unit per 2 or 3 seconds ( 2 for $\mathrm{L}$ and 3 for $\mathrm{M}, \mathrm{H}$, and $\mathrm{S}$ ). For deceleration it is important to distinguish between an airplane on the runway and an airplane on the taxiway. On the taxiway the deceleration is unlimited. On the runway the deceleration is one unit per 2 to 4 seconds ( 2 for $\mathrm{L}, 3$ for $\mathrm{M}$ and $\mathrm{H}$, and 4 for $S)$.

Randomization is a relevant issue for airplanes taxiing on a taxiway network. It occurs while taxiing on taxiways from runway to gate or from gate to runway. There are several reasons for this randomization:

- Multiple parallel tasks: While taxiing to the departure runway pilots have to read checklists carefully, talk to air traffic control (ATC) via radio to receive clearances for crossing runways etc. and discuss the given departure route.

- Preparation for the next flight: Pilots of arriving airplanes often start preparing for the next flight while taxiing to the gate in order to shorten ground time. This is especially significant for short distance flights.

- Ignorance of the airport: Pilots perform flights to various airports. Taxiing routes on airports are given labels of run- and taxiways (letters and numbers) through ATC and have to be understood by using special maps. This can lead to deceleration or even stopping on taxiways. 


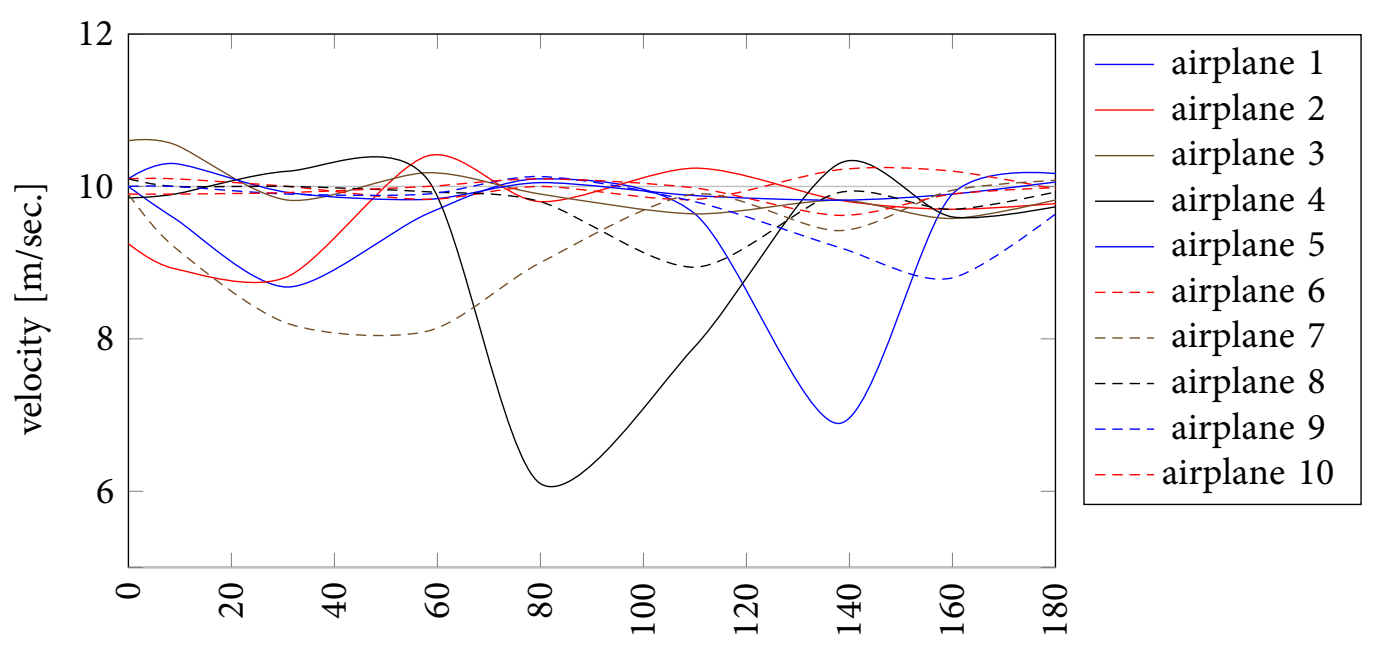

time until passing checkpoint 5 on taxiway $\mathrm{M}$ [sec.]

Figure 1 Speed-time plot of 10 airplanes taxiing on taxiway M. The single plots are interpolated curves above the values calculated between checkpoints. Second zero on the time axis is the point of airplanes passing checkpoint 5 on taxiway $\mathrm{M}$ and taxi toward runway 23L. Only airplanes taxiing without external influences are shown. A speed drop can be seen in nearly every single airplane plot.

In Fig. 1 the interpolated velocity-time plot exemplary for 10 airplanes taxiing on taxiway $M$ without external influences is shown. A speed drop can be seen in nearly every single plot. Due to an airplane's high weight these fluctuations last longer than the fluctuations in car traffic which are typically implemented by a duration of $1 \mathrm{~s}$ [5]. A value of $10 \mathrm{~s}$ is a good average value according to visual observations and the assessment of tower agents.

To quantify the fluctuation's influence on taxiing times a comparison between optimum times (with constant speed $10 \mathrm{~m} / \mathrm{s}$ ) and real times (collected through visual observation at the airport of Duesseldorf) was carried out. Therefore all collected taxiing times of various hours with different characteristics (daytime, season) were summed. A probability of $1 \%$ for arriving airplanes and $3 \%$ for departing airplanes reproduce the collected data on a high exactness.

According to the original Nagel-Schreckenberg-Model the rules can be described as follows:

$v_{n_{\max }}=$ maximum speed of airplane $n$ according to movement type (taxiing, take-off, landing)

$v_{\text {taxi }}=$ standard speed of taxiing on taxiways ( 2 cells per second $)$

$t_{n}^{\mathrm{A}}=$ time required for one unit of acceleration due to classification of airplane $n$ according to ICAO

$t_{n}^{\mathrm{D}}=$ time required for one unit of deceleration on the runway due to classification of airplane $n$ according to ICAO 
$d_{n}=$ actual distance from airplane $n$ to next airplane in front of airplane $n$

$p_{n}=$ probability of airplane $n$ for randomization on taxiways ( $1 \%$ for arriving airplanes and $3 \%$ for departing airplanes)

- Step 1: Acceleration

If airplane has not accelerated in last $t_{n}^{\mathrm{A}}$ timesteps and is not on runway after landing

$$
v_{n} \rightarrow v_{n}^{\prime}=\min \left(v_{n}+1, v_{n_{\max }}\right),
$$

else

$$
v_{n} \rightarrow v_{n}^{\prime}=v_{n}
$$

- Step 2: Deceleration

If airplane is on taxiway

$$
v_{n}^{\prime} \rightarrow v_{n}^{\prime \prime}=\min \left(v_{n}^{\prime}, d_{n}\right),
$$

else if airplane is on runway and has not decelerated in last $t_{n}^{\mathrm{D}}$ timesteps

$$
v_{n}^{\prime} \rightarrow v_{n}^{\prime \prime}=\max \left(v_{n}^{\prime}-1, v_{\text {taxi }}\right),
$$

else

$$
v_{n}^{\prime} \rightarrow v_{n}^{\prime \prime}=v_{n}^{\prime}
$$

- Step 3: Randomization

If airplane is on taxiway and did not reduce speed due to randomization in last $10 \mathrm{~s}$

$$
v_{n}^{\prime \prime} \rightarrow v_{n}^{\prime \prime \prime}= \begin{cases}\max \left(v_{n}^{\prime \prime}-1,0\right) & \text { with probability } p_{n} \\ v_{n}^{\prime \prime} & \text { with probability } 1-p_{n}\end{cases}
$$

else

$$
v_{n}^{\prime \prime} \rightarrow v_{n}^{\prime \prime \prime}=v_{n}^{\prime \prime}
$$

- Step 4: Taxiing

Airplane $n$ taxies with new speed $v_{n}(t+1)=v_{n}^{\prime \prime \prime}$ exactly $v_{n}(t+1)$ cells

$$
x_{n}(t+1)=x_{n}(t)+v_{n}(t+1) \text {. }
$$

Minimum distance and convergence of airplanes on the ground Airplanes on ground adhere a minimum distance of 20 cells due to the jet blast and possible damages. To avoid unnecessary breaking, the following airplane reduces its velocity to 1 cell per second if the distance gets closer than 150 cells between the airplanes. 
Crossing situations In real life ATC is responsible for all crossing situations on an airport. In the simulation the airplane arriving first at a crossing between two taxiways has the right of way. If they arrive at the same time the simulation has to dice. The crossing of runways with taxiways is very simple and only possible if the runway is free of airplanes. Otherwise the airplane on the taxiway has to stop at the holding point (a line marked on the taxiway just before the taxiway crosses the runway) and wait for permission to cross.

Pushback of airplanes The first action of a departing airplane is the pushback. The airplane has to be pushed backwards from the terminal onto the taxiway because it is not allowed to use the reverse thrust in this phase. The process of pushback normally takes 3 to 5 minutes and depends on the position of the gate used by the airplane.

Gate position The actual used gate depends on the local airport company, the airplane company which is responsible for the flight (due to strategic alliances airplanes of all related companies use the same terminal if possible) and customs (depending on the destination).

\subsection{The airport of Duesseldorf}

The international airport of Duesseldorf (ICAO code EDDL) consists of two parallel runways and was opened in 1927. In 2016, 23.5 M passengers were processed and the airport handled 217,500 airplane movements [23]. The prognosis for 2017 and 2018 is an exceedance of the $24 \mathrm{M}$ passenger mark. There are lots of crossing situations due to the layout of the airport and the limited space.

The airport's two runways are too close to each other to be operated independently because the distance is less than $1,035 \mathrm{~m}[24,25]$ (see Fig. 2). This means that take-off clearances on one runway can only be given if the second runway is free of potentially conflicting traffic.

Runways are named using a two-digit number between 01 and 36 [26]. This is the whole number closest the one-tenth of the magnetic North when viewed from the direction of approach. On parallel runways the number is supplemented with a letter ( $\mathrm{L}$ for left, $\mathrm{C}$ for center, and $\mathrm{R}$ for right), in the order shown from left to right when viewed from the direction of approach. Most runways can be used in two directions depending on the direction of wind. Airplanes always take off and land working against the wind because the relevant speed for their uplift is the airplane's velocity in relation to the surrounding air. According to this the two runways in Duesseldorf are named as followed:

- $05 \mathrm{R} / 23 \mathrm{~L}$ (the southern runway): This runway has a length of 3,000 $\mathrm{m}$ [24] and is situated near the terminal.

- 05L/23R (the northern runway): This runway has a length of 2,700 m [24]. Airplanes have to cross the southern runway to reach the northern runway. 


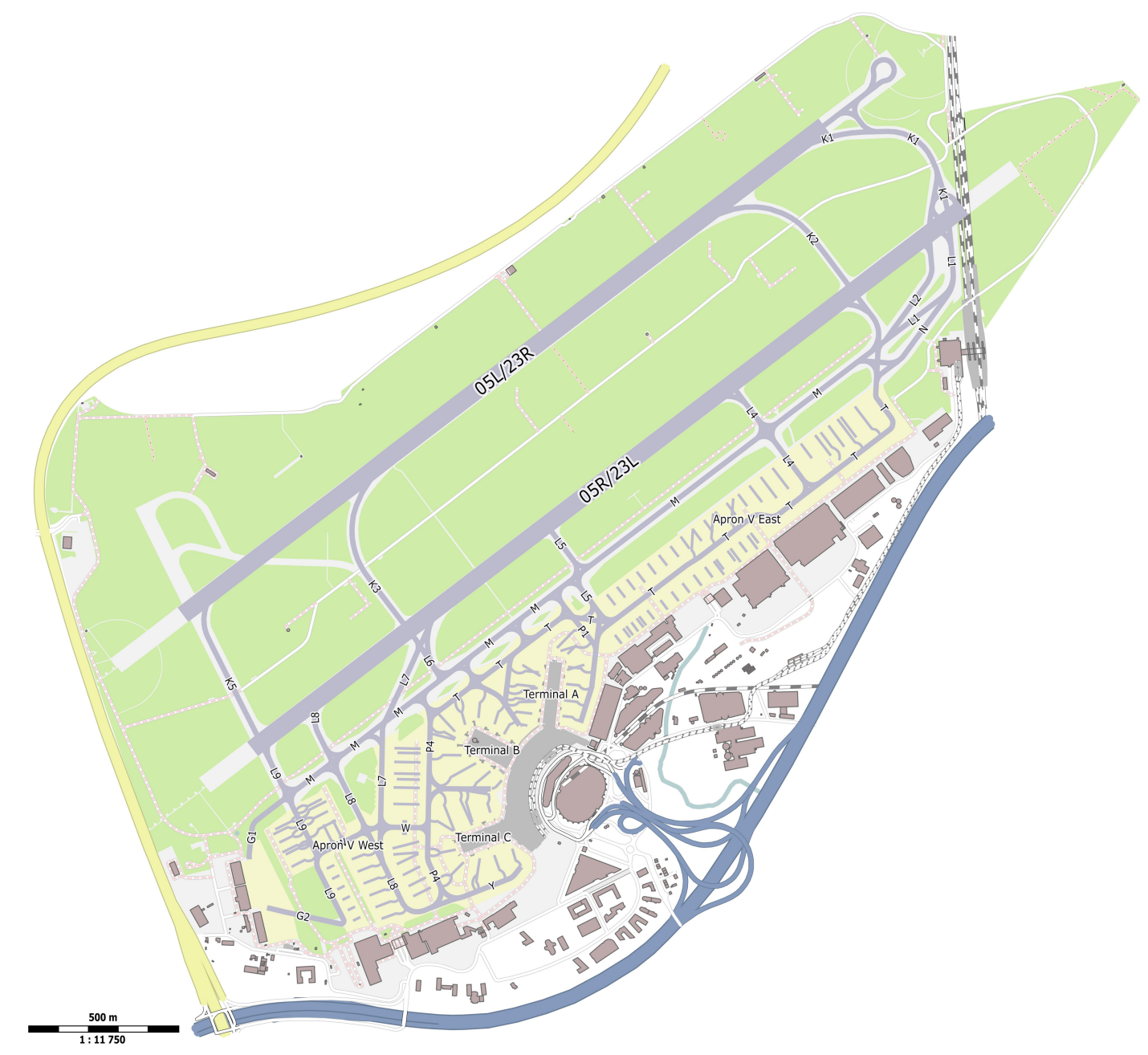

Figure 2 Layout of Duesseldorf Airport. The airport consists of two parallel runways (05R/23L and 05L/23R) and one main taxiway (M). Furthermore there is one passenger terminal with terminal parts $\mathrm{A}, \mathrm{B}$, and $\mathrm{C}$ and a main apron, the apron west and the apron east. (Source: OpenStreetMap contributors (Licence ODbL) [22])

If the prevailing wind direction is west or south the direction of operation is called 05 (according to the names of the runways). If it is north or east the direction of operation is called 23. This is important due to the asymmetric layout of the airport.

In 1965 the airport and the nearby towns reached a settlement for reducing noise pollution by limiting airplane movements. This settlement, called the "Angerlandvergleich" [27], is a unique fact about the airport. On the basis of the "Angerlandvergleich" the following relevant restrictions for using the second runway built in 1997 exist: first, the airport is allowed to use the second runway only half-time. Second, the local government determines the usage times one week in advance. According to this, two different ways of operation have to be distinguished at the airport of Duesseldorf:

- Single-runway-operation (SRO): Only one runway is allowed to be used for takeoffs and landings. If there is no construction work or technical problem runway 
05R/23L (the southern runway) is used in this case because of the runway length.

- Dual-runway-operation (DRO): Both runways are allowed to be used. Normally runway $05 \mathrm{R} / 23 \mathrm{~L}$ (the southern runway) is used for take-offs and runway $05 \mathrm{~L} / 23 \mathrm{R}$ (the northern runway) is used for landings. Only the Airbus 380 has to land on the southern runway because the northern runway has no permission for landings of this type due to the length.

In SRO the capacity limit is 43 airplane movements (take-off and landing) and in DRO 47 airplane movements [28]. The increase of only four airplanes is the result of the dependency in operation between the runways because of the distance in between.

\subsection{Real-world data from the airport of Duesseldorf}

As input for the CAMAT-Model real-world data from the airport of Duesseldorf is needed. The biggest challenge is radar only providing pictures with numbers of disturbances due to radar shadow. In addition, it is difficult to distinguish between small airplanes and ground facilities, such as busses, without additional information. The identification by the airplanes' transponder is mostly not possible because some airplanes power the transponder on just before line-up on the runway. As a result, visualization systems such as flightradar24 [29] only map a subset of the airplanes (see Fig. 3). Furthermore, there is no multilateration detection system currently installed on the airport of Duesseldorf like on the airport of Tokio mapping airplanes and vehicles every second with an accuracy of $7.5 \mathrm{~m}$. It is planned to install an "Advanced Surface Movement Guidance and Control System" [30] in the next years. Hence, at the present time only visual observation is possible on the airport of Duesseldorf.

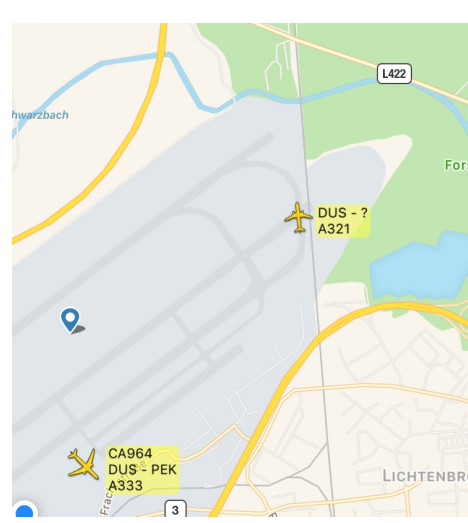

(a)

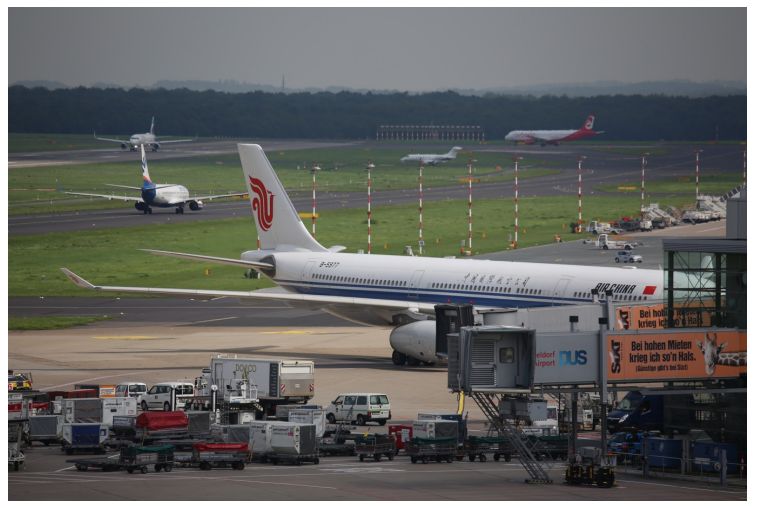

(b)

Figure 3 Comparison of flightradar24 (a) and a picture (b) taken at the same time. In (a) two airplanes are mapped: an Air Berlin Airbus 321-200 in front of the runway and an Air China Airbus 330300, which is currently pushed. In (b) three more airplanes can be seen: a Sun Express Boeing 737-800 on taxiway M, a learjet on taxiway L3 and a Eurowings Airbus 320-200 on the runway. (Source: flightradar24 [29] and own picture) 
To obtain relevant information, passing times are collected for airplanes at defined checkpoints (crossings of taxiways or taxiways with runways, see Fig. 4). As a result taxiing times are obtained for every section on taxiway and runway.

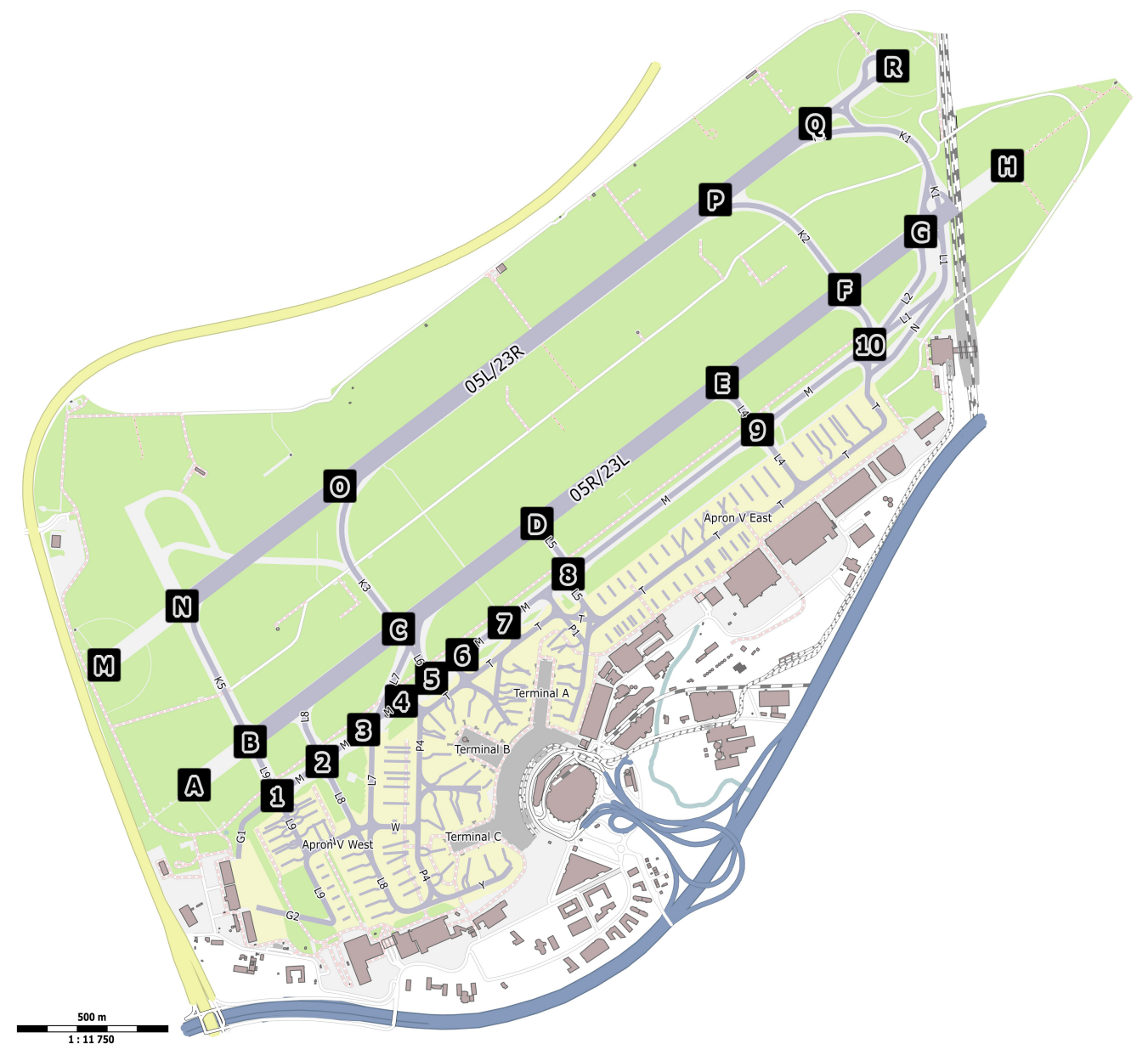

Figure 4 Checkpoints defined at Duesseldorf Airport. The checkpoints on runways are named by letters, whereas checkpoints on taxiways are named by numbers. (Source: OpenStreetMap contributors (Licence ODbL) [22])

In Fig. 5 the pictures are taken at the time of passing the following checkpoints:

- (a) $\leftrightarrow$ Checkpoint $7 \leftrightarrow 11: 14: 59$

- (b) $\leftrightarrow$ Checkpoint $8 \leftrightarrow 11: 15: 21$

- (c) $\leftrightarrow$ Checkpoint $9 \leftrightarrow 11: 16: 36$

- (d) $\leftrightarrow$ Checkpoint $10 \leftrightarrow 11: 17: 30$

- (e) $\leftrightarrow$ Checkpoint $\mathrm{G} \leftrightarrow 11: 19: 20$

- (f) $\leftrightarrow$ Checkpoint $\mathrm{F} \leftrightarrow 11: 20: 31$ 
- $(\mathrm{g}) \leftrightarrow$ Checkpoint $\mathrm{E} \leftrightarrow 11: 20: 42$

- (h) $\leftrightarrow$ Checkpoint D $\leftrightarrow 11: 20: 53$

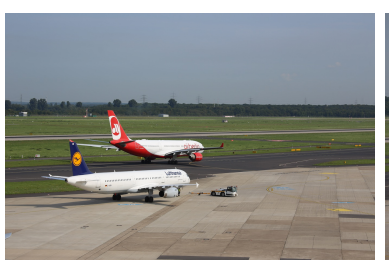

(a)

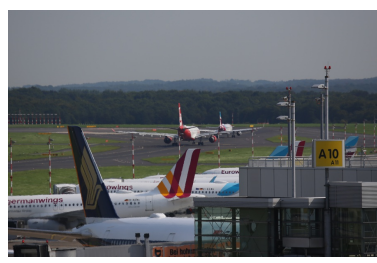

(d)

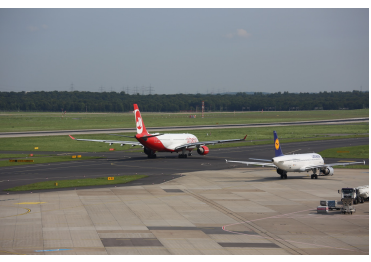

(b)

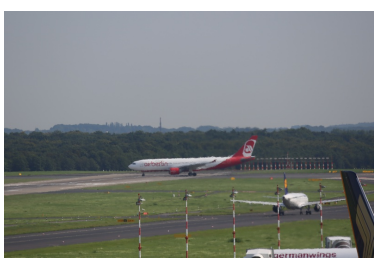

(e)

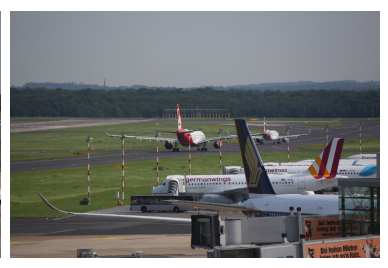

(c)

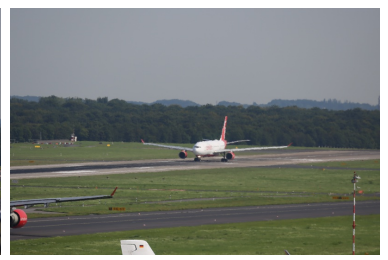

(f)

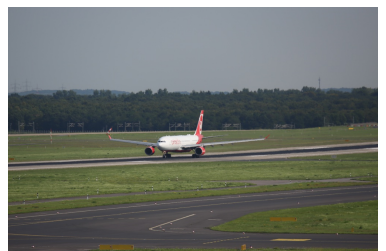

(g)

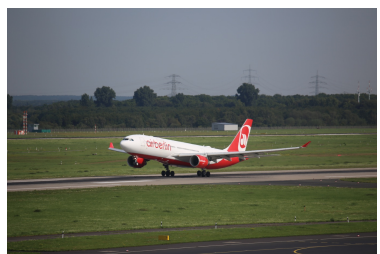

(h)

Figure 5 Collecting data through visual observation. The times of passing the checkpoints are noted and taxiing times between the checkpoints are calculated. (source: own pictures)

The obtained taxiing times are shown in Tab. 2. On each runway airplanes can take off and land in two directions depending on the direction of the wind. The data of each direction of operation has to be collected independently. Furthermore a differentiation between SRO and DRO is important to obtain relevant data.

\begin{tabular}{lccccccc}
\hline section & $7-8$ & $8-9$ & $9-10$ & $10-G$ & G-F & F-E & E-D \\
\hline taxiing-time [s] & 22 & 75 & 54 & 110 & 71 & 11 & 11 \\
\hline
\end{tabular}

Table 2 Taxiing times of an Air Berlin Airbus 330-200. In the top line the sections are displayed; in the bottom line the corresponding taxiing times are presented.

This data is complemented by data of ATC. Above all information about gates and routes used by the airplanes is an important issues. It should be noted that especially the taxiing routes are the result of tower agents' long-term experience. These are not documented. The routes used in the simulation are set as a result of intensive discussions with the agents on the tower of Duesseldorf airport. 
A comparison between real-world data and simulation was realized on both runways. Data from each runway was compared for both directions of operation with the necessary distinction between SRO and DRO. The following figures represent a selection of all comparisons.

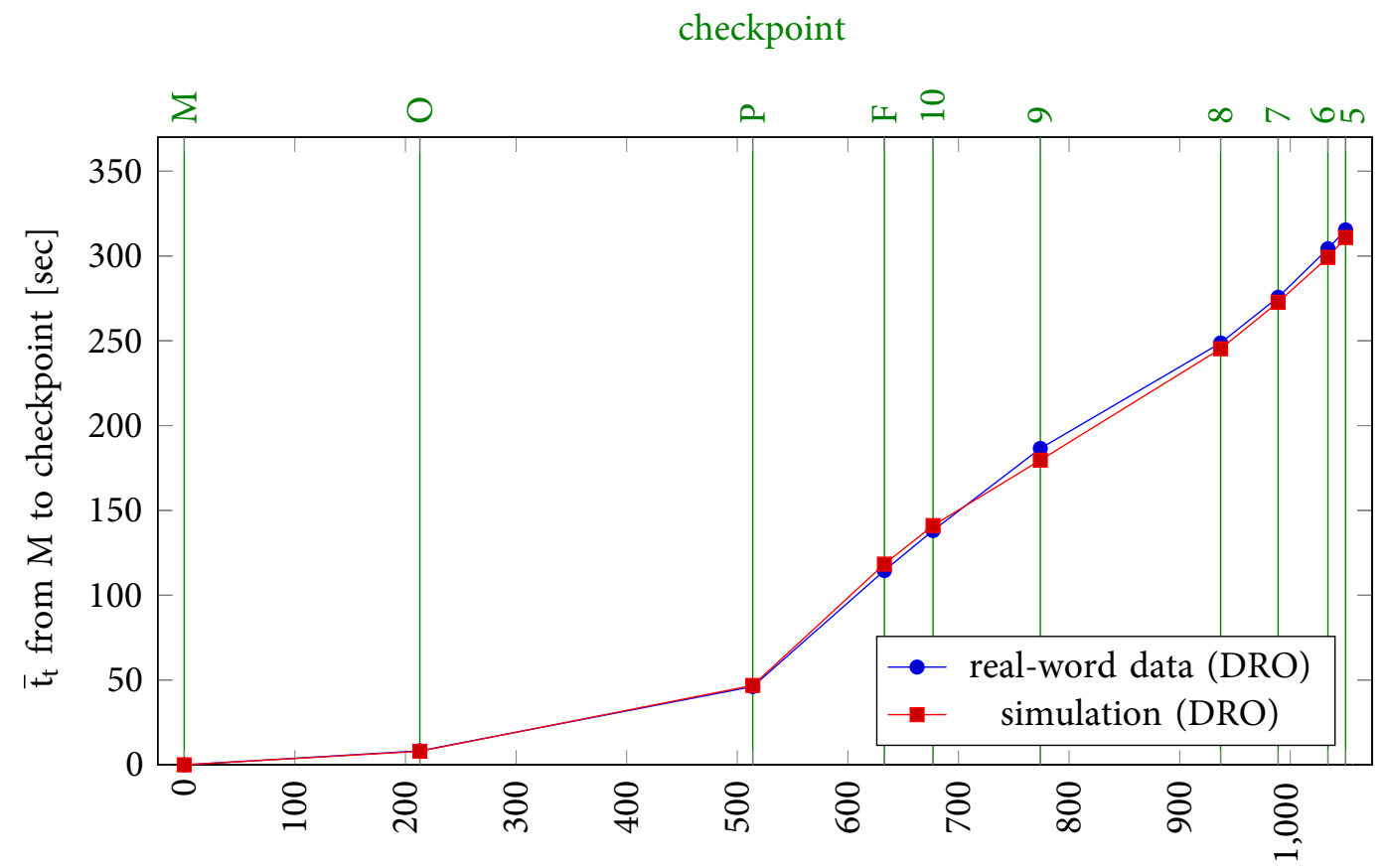

distance, starting at checkpoint $\mathrm{M}$ [cells]

Figure 6 Comparison real-world data and simulation for arriving aircrafts on runway 05L (DRO) taxiing via $\mathrm{K} 2$ to checkpoint 5 on taxiway $\mathrm{M}$ at the airport of Duesseldorf.

Figure Fig. 6 presents the comparison for arriving airplanes on runway 05L in DRO (in SRO runway $05 \mathrm{~L}$ is not used). On the $\mathrm{x}$-axis the distance starting at checkpoint $\mathrm{M}$ on the runway and on the $y$-axis the averaged taxiing time starting when passing checkpoint $M$ is plotted. In addition the position of all passed checkpoints is marked with green lines. The averaged trajectories of real-world and simulated data are very similar and differ only slightly. The slope of the trajectories shows the airplane's velocity. An increased slope indicates a decreased velocity.

Figure Fig. 7 shows the same comparison but for departing airplanes on runway 05R. This runway is used for departing airplanes in SRO and DRO. The direct comparison shows a lower taxiing time for airplanes in DRO due to the higher capacity of the airport in this mode. 
checkpoint

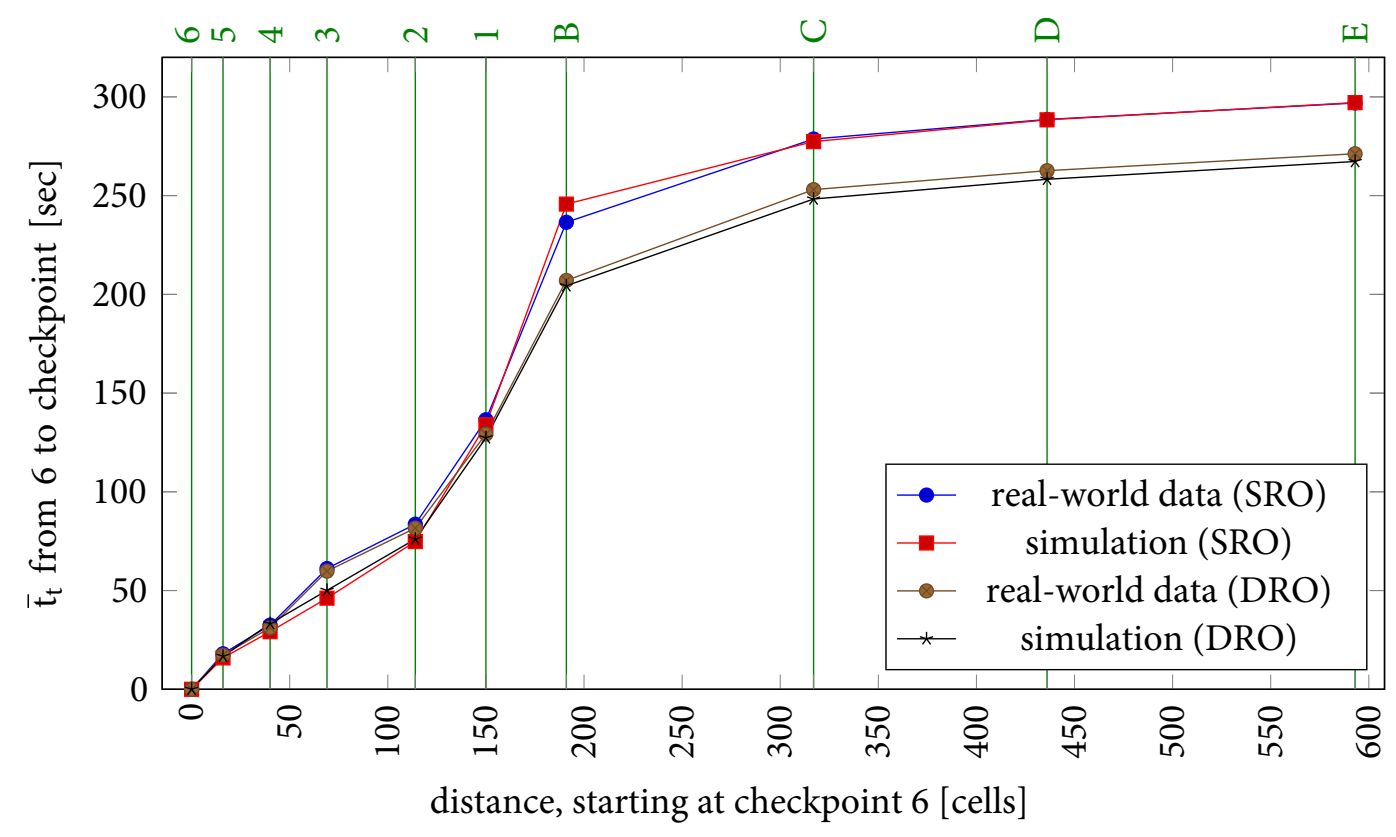

Figure 7 Comparison real-world data and simulation for departing airplanes on runway 05R (SRO and DRO) starting at checkpoint 6 on taxiway $\mathrm{M}$ at the airport of Duesseldorf.

\section{Simulation and optimization of airplane traffic at the airport of Duesseldorf}

In this section a simulation of closures of taxiways and an optimization through changing the layout is presented. Taxiing times are compared to original times without construction work or optimization.

The taxiing times presented in this chapter are the result of a number of simulations. Each simulation uses the following real-life input data:

- airplanes' arrival times,

- time of starting pushback for departing airplanes,

- taxiing routes for arriving and departing airplanes as used by ATC (for simulations without closures or optimization).

To make the result most realistic 10 independent sets of data, each containing the realistic sequence on the airport of Duesseldorf for one hour at peak hours, are used. They were recorded on different weekdays and seasons.

The simulations are distinguished by SRO and DRO. Furthermore the results of the simulations have to be differentiated between the two directions of operation. This leads to four possible combinations, having to be applied to each scenario: 
- SRO and direction 05 ,

- DRO and direction 05,

- SRO and direction 23,

- $\mathrm{DRO}$ and direction 23.

In each combination taxiing times are separated for arriving and departing airplanes and summed for one hour. Each combination is simulated 100 times for one set of data. The outputs of the resulting 1,000 simulations are averaged. Altogether, this leads to 4,000 simulations for one scenario.

The figures in this chapter present the changes in taxiing times occurring when applying a scenario compared to the taxiing times without this scenario.

\subsection{Simulation of taxiway closures due to construction work}

In this scenario the runway exits for leaving the runway after touchdown are closed resulting in the fact that airplanes cannot exit the runway via K2 and L3 when runway 05 is in use or via K3, L6 and L7 when runway 23 is in use (see Fig. 8). All arriving traffic normally leaving the runway at the now closed exits has to taxi to the end of the runway. As a result, the following possibilities to exit remain:

- Runway 05L: exit via K1 and L1

- Runway 05R: exit via L1 or L4

- Runway 23L: exit via L5, L8 or L9

- Runway 23R: exit via K5 and L9

The new taxiing routes are realistic routes which tower operators would use in this case. Every taxiway and runway has to be closed from time to time for renovation work, so that operators had to deal with a comparable situation in the past. This expert knowledge has been exploited for determining the modified taxiing routes.

The closures hardly have an effect on taxiing times of departing airplanes as they mostly start their take-off process at the beginning of the runway. Impacts can only be expected during taxiing from terminal to runway. These impacts have to be analyzed separately for both directions (05 / 23) and modes of operation (SRO / DRO).

Fig. 9 presents the results of simulating this scenario, clarifying that taxiing times for all modes of operation and direction increase. It is obvious that the degree of increase differs. On the right axis in Fig. 9 averaged increase in fuel consumption can be seen. These numbers are based on the consumption of an Airbus 320, which is the most common airplane at the airport of Duesseldorf and are summed and averaged for one hour of operation. 


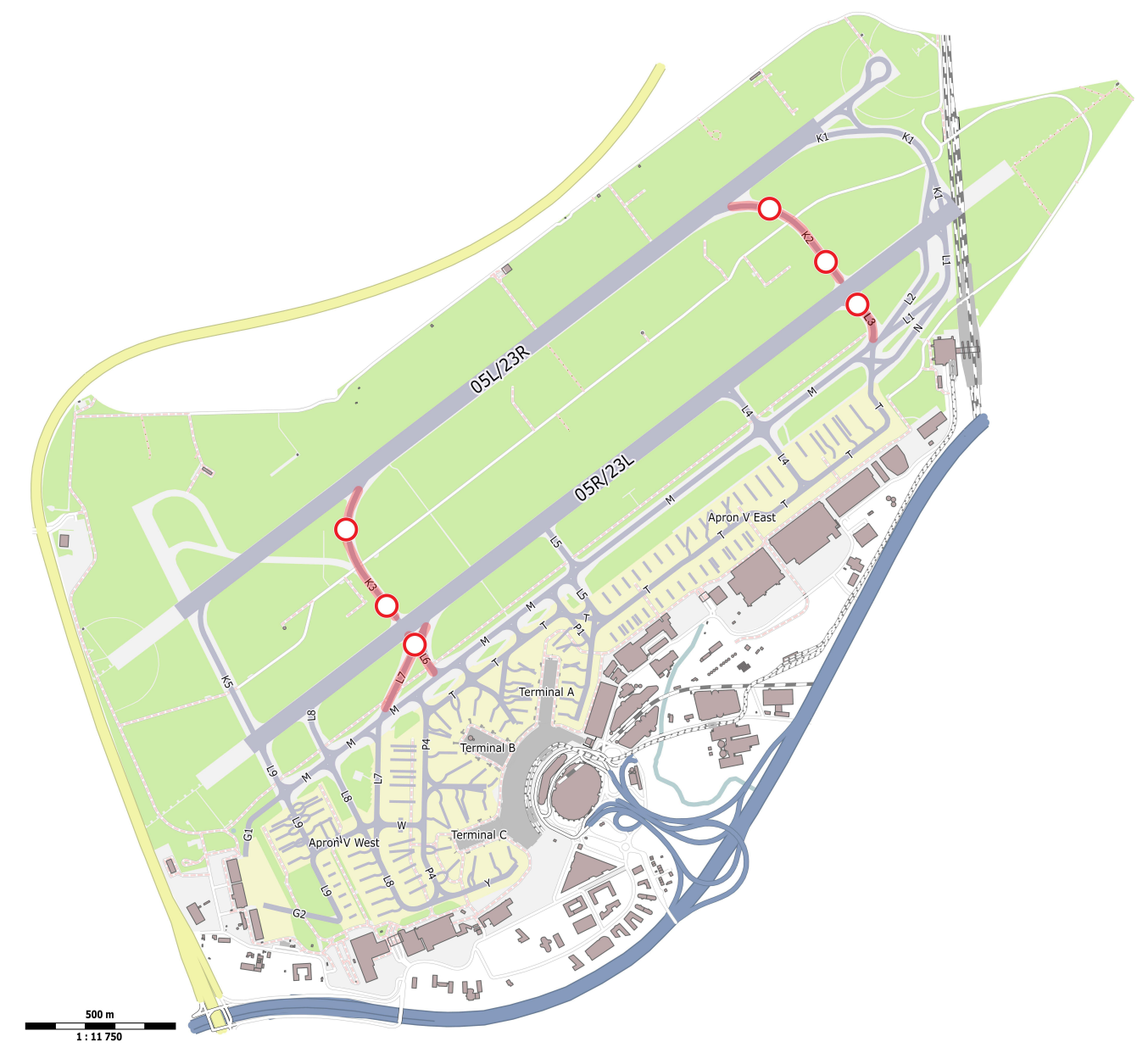

Figure 8 Closure of runway exits K2 and L3 (relevant if runway 05 is in use), as well as runway exits L3 and L6/L7 (relevant if runway 23 is in use). (Source: OpenStreetMap contributors (Licence ODbL) [22])

Direction of operation 05 The averaged increase per hour of the taxiing times for departing airplanes is $52 \mathrm{~s}$ in SRO and $62 \mathrm{~s}$ in DRO. This slight increase is a result of the fact that arriving airplanes need more time to vacate the runway because of the longer way to the end of the runway. Due to the dependency of operating two runways in DRO, the use of the second runway does not result in reducing this effect.

For arriving airplanes the increase per hour of the taxiing times is $160 \mathrm{~s}$ in SRO and $1.099 \mathrm{~s}$ in DRO. The increase in SRO is a result of the longer taxiing routes because of the closure of taxiway L3. All airplanes normally leaving the runway via L3 have to taxi to the end of the runway and exit there. Due to the fact that there is another taxiway L4 in front of L3, smaller airplanes leave the runway in the same way as if there were no closure of L4. Only heavier airplanes have to extend their taxiing on the runway. In DRO all airplanes land on runway 05L. Normally there are two possibilities to vacate the runway, K1 and K2. Due to the closure of K2 there is no alternative to K1 left. All airplanes have to vacate runway $05 \mathrm{~L}$ via $\mathrm{K} 1$ and $\mathrm{L} 1$. This leads to a significant increase 

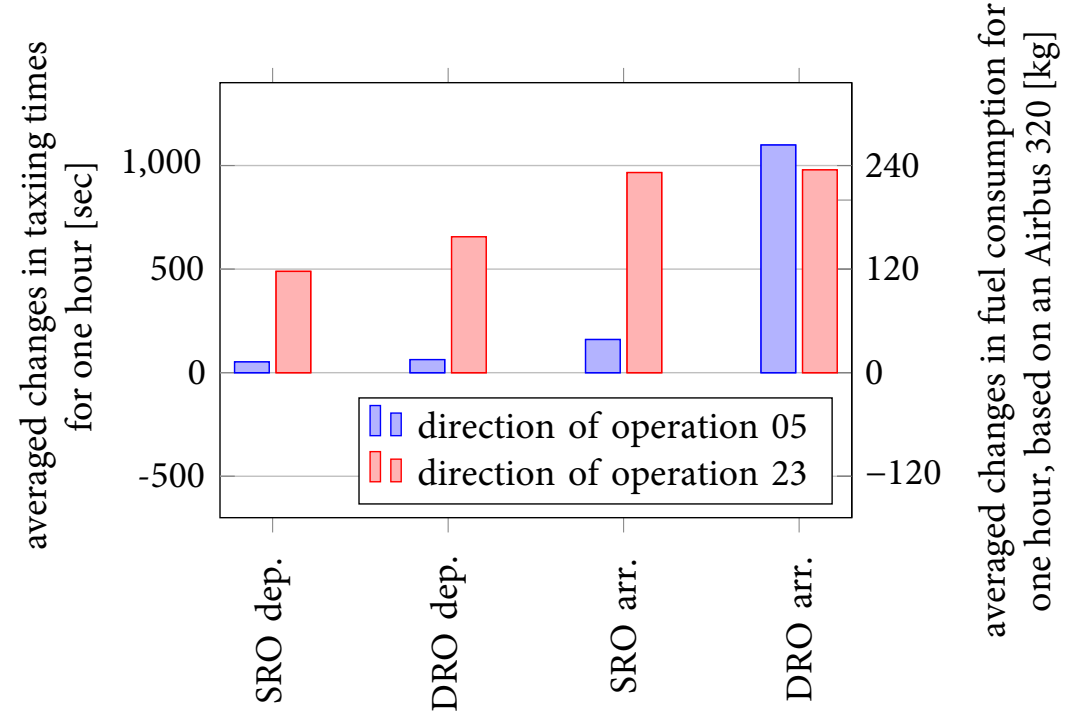

Figure 9 Averaged changes in taxiing times for one hour of operation while closure of taxiways K2 and L3 (runway 05 in use), respectively K3, L6 and L7 (runway 23 in use). The taxiing times are compared to the averaged times of taxiing without disturbance. On the right extra fuel consumption for one hour is displayed, based on the averaged consumption rate of an Airbus 320.

in taxiing times compared to SRO, especially for smaller airplanes.

Direction of operation 23 Compared to direction of operation 05, direction 23 shows a varying development when closing taxiways K3, L6 and L7. The increase for departing airplanes is higher (489 s in SRO and $656 \mathrm{~s}$ in DRO) because of the layout of the airport. The terminal and the main apron are situated at the west part of the area, near to the runways. There is no chance to pass this area except passing on taxiway $\mathrm{M}$. This leads to a significantly higher interaction between departing and arriving airplanes and an increase of their taxiing times because of waiting times.

Arriving airplanes in direction 23 require 966 s more in SRO and 979s more in DRO in one hour of operation. This increase in both modes of operation results from the layout of the airport. In contrast to SRO in direction 05, all airplanes landing in direction 23 have to interact with departing airplanes and lose time while waiting for cleared taxiways and crossing situations.

\subsection{Optimization through changing the layout}

This scenario deals with a possible extension of the taxiway network. The impact of a new proposed taxiway $\mathrm{N}$ which runs parallel to the runways and taxiway $\mathrm{M}$ is analyzed (see Fig. 10). Some parts of the new runway $\mathrm{N}$ are already built. In the eastern part of the airport the beginning of taxiway $\mathrm{N}$ is already in use but ends at taxiway $\mathrm{T}$ at the beginning of apron $\mathrm{V}$ east. This taxiway would be extended and culminate in taxiway $\mathrm{T}$ west of taxiway P1. West of P4 a new part has to be built until terminating at taxiway L9. 


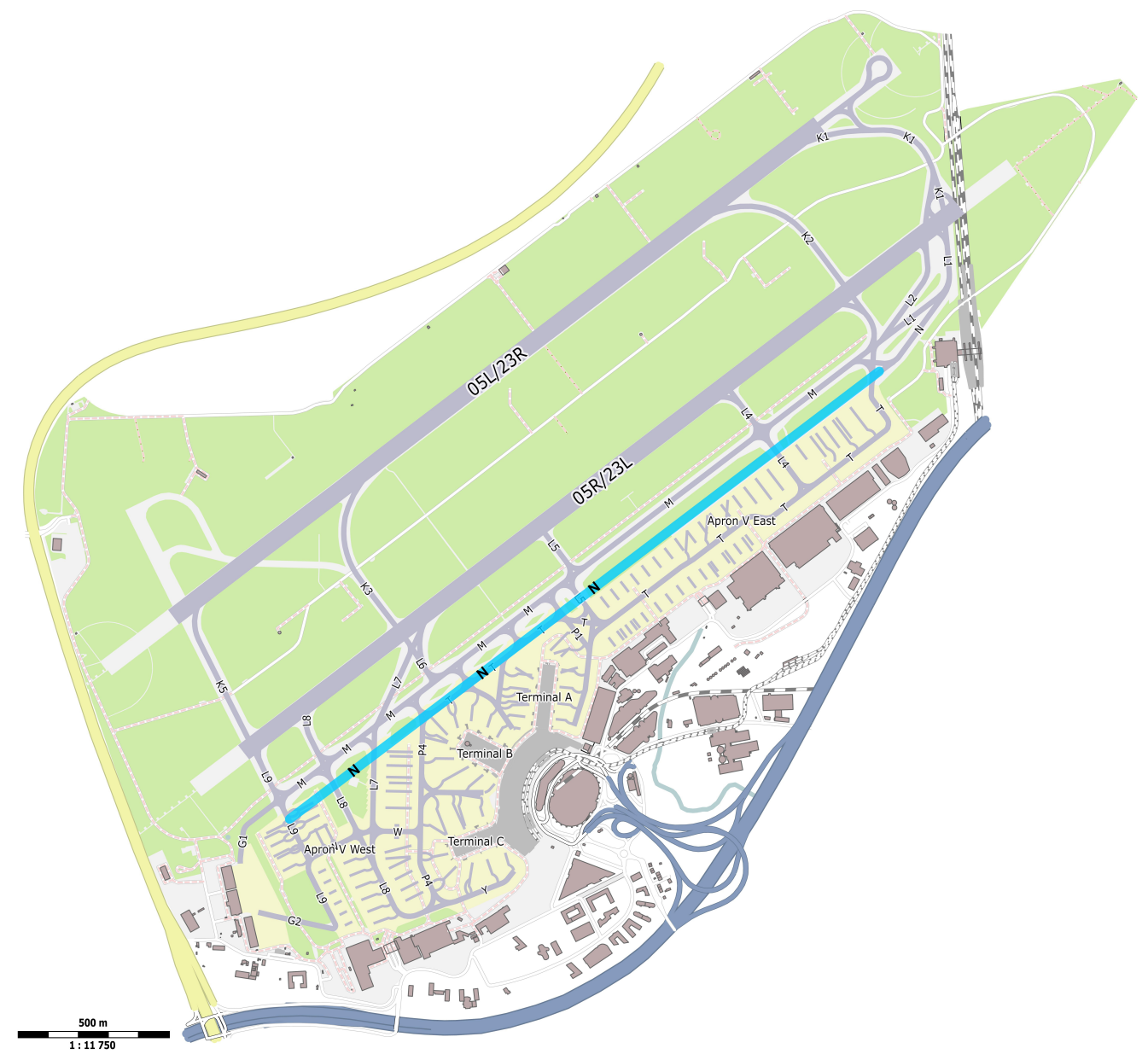

Figure 10 Addition of a new taxiway N, parallel to the runways and taxiway M. (Source: OpenStreetMap contributors (Licence ODbL) [22])

Due to this new taxiway the airport could operate in a more flexible way. The fact that only one taxiway actually exists is one of the airport's main weaknesses. An appropriate measure of extension is the tower crew's main request for the future.

According to the tower crew taxiways $\mathrm{M}$ and $\mathrm{N}$ would be used in different directions for taxiing in case of extension. All adjusted taxiing routes for this scenario are results of locals' expert opinions involved in working in the tower at the airport of Duesseldorf. The impacts of this new taxiway $\mathrm{N}$ are analyzed below to demonstrate the meaningfulness of this measure.

Fig. 11 shows the results of simulating the second scenario. In contrast to the first scenario taxiing times for all modes of operation and direction decrease in different degrees. On the right axis in Fig. 11 averaged decrease of fuel consumption is shown. These numbers are based on the consumption of an Airbus 320 and are summed and averaged for one hour of operation like in the first scenario. 


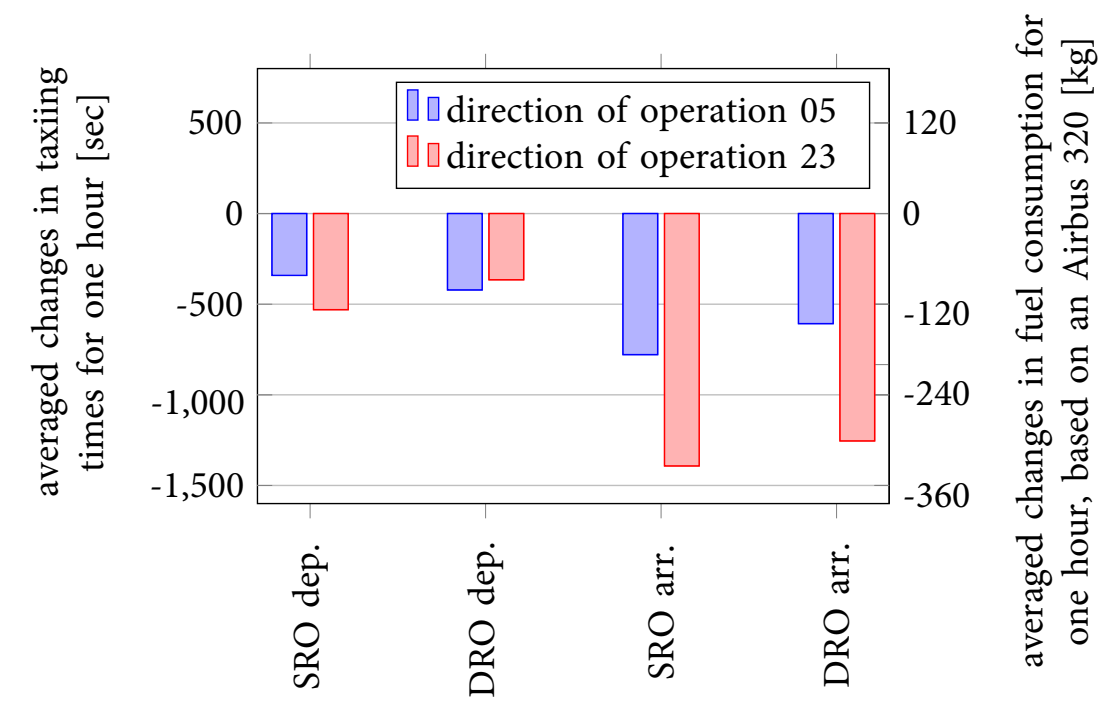

Figure 11 Averaged changes in taxiing times for one hour of operation after adding a new taxiway N, parallel to the runways and taxiway $\mathrm{M}$. The taxiing times are compared to the averaged times of taxiing without extensions. On the right saving of fuel consumption for one hour is displayed, based on the averaged consumption rate of an Airbus 320.

Direction of operation 05 Airplanes departing in direction 05 have an averaged decrease of $341 \mathrm{~s}$ of taxiing time in SRO and of $421 \mathrm{~s}$ in DRO per hour. Arriving airplanes show a reduction of taxiing time of $778 \mathrm{~s}$ in SRO and of $607 \mathrm{~s}$ in DRO. These decreases are the result of the unbundling of departing and arriving traffic due to the second parallel taxiway N. There are much less crossing situations between the airplanes and nearly no need to stop and wait for cleared taxiways.

Direction of operation 23 In direction 23 the reduction for departing airplanes is $503 \mathrm{~s}$ in SRO and $365 \mathrm{~s}$ in DRO. The reduction for arriving traffic is $1392 \mathrm{~s}$ in SRO and $1254 \mathrm{~s}$ in DRO. Again, this is the direct result of the separation of inbound and outbound traffic nearly until arriving at the gate. The higher rate of reduction in contrast to direction 05 can be explained by the asymmetrical layout of the airport. This leads to a different degree of reduction between the direction of operation due to avoiding more crossing situations after building the second parallel taxiway in direction 23 .

\section{Conclusion and Outlook}

In this paper the CAMAT-Model (Cellular Automaton Model for Airplane Traffic) and some application examples are presented to show the possibility of a realistic airport ground traffic simulation at the airport of Duesseldorf. The characteristics of the model are explained and examples for its utilization are given.

The adjustment of the simulated results with real-world data is conducted by data of visual observations from the airport of Duesseldorf combined with data of ATC. As a 
result the averaged aberration of the CAMAT-Model is maximally $3 \%$ (typically 1-2\%) when comparing simulated taxiing times with real-world data at peak hours. By using the model, simulating new taxiing routes on the actual layout of an airport and simulating new airport layouts in advance becomes possible.

Two examples of utilization are given. First, a scenario with closures of taxiways, for instance due to renewal of asphalt, is given. A second scenario deals with a possible extension of the taxiway network and presents the results of building a second parallel taxiway. The adjustments of taxiing routes are the result of expert assessments by the crew of the tower in Duesseldorf and are based on experience. The changes in taxiing times show the effects on taxiing time for these scenarios and help to estimate the consequences for the airport.

The German air-traffic-control and the airport Duesseldorf $\mathrm{GmbH}$ have valued the results of the simulations and shown strong interest in cooperating with the university to accompany their airport planning in the future, especially in the numerous cases of taxiway or apron work. This will help to further refine the model and have definite applications for this research.

Moreover extensions of the model will deal with the implementation of ground facility traffic, like fuel vehicles, Follow-Me-Cars, busses, etc. and the simulations of new airplane systems, like the Break to Vacate system (BTV) [31], which is a subset of the airplane's flight computer. It allows the computer to be programmed for a pre-selected stopping distance, indicating the required combination of brakes and thrust reversers to achieve that distance.

Acknowledgements The authors would like to thank the German air-traffic-control (Deutsche Flugsicherung, DFS), especially the crew of the control tower in Duesseldorf, and the airport of Duesseldorf (Flughafen Düsseldorf $\mathrm{GmbH}$ ) for their valuable comments and lots of undocumented information on airplane taxi operations at Duesseldorf airport and for assisting with optimizing the CAMAT-Model as well as including all relevant elements of airplane taxiing.

\section{References}

[1] Bundesministerium für Verkehr und digitale Infrastruktur: Verkehrsverflechtungsprognose 2030. Internet (2014). URL http://www. bmvi.de/SharedDocs/DE/Anlage/VerkehrUndMobilitaet/ verkehrsverflechtungsprognose-2030-zusammenfassunglos-3.pdf

[2] DFS Deutsche Flugsicherung: Luftverkehr in Deutschland - Mobilitätsbericht 2016. Internet (2017). URL https://www.dfs.de/dfs_homepage/de/ Presse/Publikationen

[3] Esser, J., Schreckenberg, M.: Microscopic simulation of urban traffic based on cellular automata. International Journal of Modern Physics C 8(05), 1025-1036 (1997). 
[4] Kretz, T.: Pedestrian Traffic Simulation and Experiments. PHD-Thesis, University Duisburg-Essen (2006)

[5] Nagel, K., and Schreckenberg, M.: A cellular automata model for freeway traffic. J. Physique I 2, 2221-2229 (1992). doi:10.1051/ jp1:1992277

[6] Schadschneider, A., Schreckenberg, M.: Cellular automation models and traffic flow. Journal of Physics A: Mathematical and General 26(15), L679 (1993). doi:10.1088/0305-4470/26/15/011

[7] Yang, B., Monterola, C.: A General Scheme for Deterministic Microscopic Traffic Models. Part I: Theoretical Construction. In: Traffic and Granular Flow'15, pp. 451-458. Springer (2016)

[8] Jeppesen: Total Airspace and Airport Modeler (TAAM). Internet (2015). URL http://ww1.jeppesen.com/documents/aviation/government/ TAAM-Fact Sheet.pdf

[9] Wood, Z., Rathinam, S., Jung, Y., Kistler, M.: A simulator for modeling aircraft surface operations at airports. In: AIAA Modeling and Simulation Technologies Conference, p. 5912 (2009)

[10] Daganzo, C.: The cell transmission model, part II: network traffic. Transportation Research Part B: Methodological 29(2), 79-93 (1995). doi:10.1016/0191-2615(94)00022-R

[11] Daganzo, C.: Urban gridlock: Macroscopic modeling and mitigation approaches. Transportation Research Part B: Methodological 41(1), 49-62 (2007). doi:10.1016/j.trb.2006.03.001

[12] Yang, L., Yin, S., Han, K., Haddad, J., Hu, M.: Fundamental diagrams of airport surface traffic: Models and applications. Transportation Research Part B: Methodological 106, 29-51 (2017). doi:10.1016/j.trb.2017.10.015

[13] Mori, R.: Aircraft taxiing model at congested airports. International Congress of the aeronautical sciences 28, 1-9 (2012)

[14] Mori, R.: Aircraft ground-taxiing model for congested airport using cellular automata. IEEE Transactions on Intelligent Transportation Systems 14(1), 180-188 (2013). doi:10.1109/TITS.2012.2208188

[15] International Civil Aviation Organization (ICAO): International Standards and Recommended Practices - Annex 16: Environmental Protection. Internet (2008). URL https://law.resource.org/pub/us/cfr/ibr/004/ icao.annex.16.v2.2008.pdf 
[16] International Civil Aviation Organization (ICAO): ICAO Aircraft Engine Emissions Databank (2017). URL https: / / www . easa . europa. eu/documentlibrary/icao-aircraft-engine-emissions-databank

[17] Morris, K.M.: Results from a number of surveys of power settings used during taxi operations. British Airways. EJT/KMM/1126/14.8 (2005)

[18] Khadilkar, H., Balakrishnan, H.: Estimation of aircraft taxi fuel burn using flight data recorder archives. Transportation Research Part D: Transport and Environment 17(7), 532 - 537 (2012). doi:10.1016/j.trd.2012.06.005

[19] Nikoleris, T., Gupta, G., Kistler, M.: Detailed estimation of fuel consumption and emissions during aircraft taxi operations at Dallas / Fort Worth International Airport. Transportation Research Part D: Transport and Environment 16(4), 302 - 308 (2011). doi:10.1016/j.trd.2011.01.007

[20] Balakrishnan, H., Jung, Y.: A framework for coordinated surface operations planning at Dallas-Fort Worth International Airport. In: AIAA Guidance, Navigation and Control Conference and Exhibit, p. 6553 (2007). doi:10.2514/6.2007-6553

[21] International Civil Aviation Organization (ICAO): Air traffic management. Internet (2001). URL http: / / www.navcanada.ca/EN/media/Publications/ ICAO-DOC-4444-EN.pdf

[22] OpenStreetMap contributors: Openstreetmap (2017). URL http://www. openstreetmap.org

[23] Düsseldorf Airport: Geschäftsbericht 2016. Internet (2017). URL https://www.dus.com/de-de/konzern/unternehmen/zahlenund-fakten//\%7E/media/fdg/dus_com/konzern/unternehmen/ zahlen_und_fakten/geschaeftsbericht/dus_gb_2016_lr.pdf

[24] Düsseldorf Airport: Flugbetrieb am Düsseldorfer Flughafen. Internet (2015). URL https://www.dus.com/ /media/fdg/dus_com/konzern/ nachbarn/flugbetrieb/pdfs/brosch\%c3\%BCre\%20flugbetrieb\% $202015 \cdot p d f$

[25] International Civil Aviation Organization (ICAO): Manual on Simultaneous Operations on Parallel or Near-Parallel Instrument Runways (SOIR). Internet (2004). URL https://www.bazl.admin.ch/dam/bazl/de/ dokumente/Fachleute/Flugplaetze/ICAO/icao_doc_9643_ manualonsimultaneousoperationsonparallelornear-par.pdf

[26] International Civil Aviation Organization (ICAO): Aerodrome Standards. Internet (1999). URL http: / / www.sightline.us/images/ICAOAnnexl4.pdf 
[27] Oberverwaltungsgericht des Landes Nordrhein-Westfalen: Protokoll eines Vergleichs (Angerlandvergleich). Internet (1965). URL https://www . dus.com/\%7E/media/fdg/dus_com/konzern/unternehmen/ kapazitaetserweiterung/pdfs/angerlandvergleich.pdf

[28] airsight GMBH: Flughafen Düsseldorf - Planfeststellungsverfahren zur Kapazitätserweiterung - Erstellung der Datenerfassungssysteme für das Referenzund das Prognoseszenario 2030. Internet (2015). URL http://www.vm.nrw . de/verkehr/luftverkehr/Planfeststellungsverfahren/6Bericht_-Erstellung-der-Datenerfassungssysteme-fuerdas-Referenz--und-das-Prognoseszenario-2030/06Erstellung-der-Datenerfassungssysteme.pdf

[29] Flightradar24 AB: flightradar24 (2017). URL http: / / www . flightradar24. com

[30] International Civil Aviation Organization (ICAO): Advanced Surface Movement Guidance and Control Systems (A-SMGCS) Manual. Internet (2004). URL https://Www.icao.int/Meetings/anconf12/Document\% 20Archive/9830_cons_en[1].pdf

[31] Tietze, S.E.: Airbus Series Vol. 1 (A318/A319/A320/A321), 1 edn. NBG EDV Handels und Verlags GmbH, Burglengenfeld (2016) 